\title{
Program Dinas Kebudayaan Sumatera Barat dalam Melestarikan Budaya Minangkabau
}

\author{
Suci Rahmadani, Hasrul \\ Prodi Pendidikan Pancasila dan Kewarganegaraan \\ FIS Universitas Negeri Padang \\ E-mail: sucir1458@gmail.com
}

\section{ABSTRAK}

Penelitian ini bertujuan untuk mendesksripsikan program Dinas Kebudayaan Sumatera Barat dalam melestarikan nilai-nilai budaya Minangkabau. Penulis menggunakan metode penelitian kualitatif deskriptif. Teknik pengumpulan data dilakukan dengan cara observasi, wawancara dan dokumentasi. Setelah data diperoleh maka di analisis melalui 4 tahap yakni mengumpulkan data, reduksi data, penyajian data dan menarik kesimpulan. Hasil penelitian menunjukkan bahwa program Dinas Kebudayaan Sumatera Barat dalam melestarikan nilai-nilai budaya Minangkabau. Pertama, program pemberdayaan dan penguatan eksistensi lembaga-lembaga adat seni dan budaya meliputi: a) penguatan adat nagari, b) penerapan nilai-nilai adat minangkabau bagi masyarakat dan generasi muda c) peningkatan wawasan adat bagi pengurus KAN dan Bundo Kanduang. Kedua, program pembinaan dan pengembangan pendidikan budaya meliputi: a) pelestarian dan aktualisasi nilai-nilai Matrilinial, b) Sosialisasi pedoman pengamalan Adat Basandi Syarak Syarak Basandi Kitabullah kepada kelompok masyarakat, c) bimtek penguatan nilainilai budaya bagi orang tua, guru dan penggiat himpunan anak usia dini, dan d) sosialisasi adat minangkabau terhadap generasi muda yang mengacu kepada Adat Basandi Syarak Syarak Basandi Kitabullah.

\section{Kata Kunci: Dinas Kebudayaan, nilai-nilai Budaya, Minangkabau}

\section{ABSTRACT}

This study aims to describe the program of the Department of Culture of West Sumatra in preserving Minangkabau cultural values. The author uses descriptive qualitative research methods. Data collection techniques were carried out by means of observation, interviews and documentation. After the data is obtained, it is analyzed through 4 stages, namely collecting data, reducing data, presenting data and drawing conclusions. The results showed that the West Sumatra Cultural Service program in preserving Minangkabau cultural values. First, the program to empower and strengthen the existence of traditional arts and cultural institutions includes: a) strengthening nagari customs, b) implementing Minangkabau traditional values for the community and the younger generation c) increasing traditional insight for KAN and Bundo Kanduang administrators. Second, the program for fostering and developing cultural education includes: a) preservation and actualization of Matrilineal values, b) Socialization of 
guidelines for the practice of the Basandi Syarak Syarak Basandi Kitabullah Adat to community groups, c) technical guidance for strengthening cultural values for parents, teachers and activists. association of early childhood, and d) socialization of Minangkabau customs to the younger generation which refers to the Basandi Syarak Syarak Basandi Kitabullah tradition.

Keywords: Department of Culture, cultural values, Minangkabau

cc) () (2) This work is licensed under the Creative Commons Attribution-ShareAlike 4.0 International License. C)2021 by author.

\section{PENDAHULUAN}

Mengingat pentingnya pelestarian kebudayaan, Negara dengan tegas menjamin kebebasan masyarakat dalam memelihara dan mengembangkan nilai-nilai budayanya, tercantum dalam Pasal 32 ayat (1) Undang-Undang Dasar Tahun 1945 tentang pemajuan kebudayaan. Untuk melaksanakan amanat Undang-Undang Dasar tersebut maka diterbitkan Undang-Undang Nomor 5 Tahun 2017 tentang pemajuan kebudayaan.

Kebudayaan adalah segala sesuatu yang berkaitan dengan cipta, rasa, dan hasil karya masyarakat. Kebudayaan dapat dibedakan berdasarkan wujudnya, yaitu budaya benda dan budaya non-benda. Budaya benda mengacu pada semua ciptaan masyarakat yang nyata, kongkret, dihasilkan dan dipakai oleh masyarakat. Sedangkan budaya nonbenda ciptaan abstrak yang diwariskan dari generasi ke genarasi sebagai pedoman atau rujukan kelompok masyarakat, yang dkuti dengan penuh kesadaran dalam bentuk nilai-nilai, norma, moral dan kepercayaan (Soerjono Soekanto, 2007).
Hal diataslah yang menjadi landasan bagi Dinas Kebudayaan Sumatera Barat dalam membuat suatu program dalam melestarikan nilainilai budaya Minangkabau agar terarahnya pengembangan kebudayaan yang lebih baik untuk memperkokoh jati diri bangsa dan kebanggaan nasional, menjadi ketahanan budaya dan dapat meningkatkan nilai-nilai kearifan yang ada dalam setiap budaya. Sumatera Barat merupakan provinsi yang kaya akan budaya yang harus dilestarikan.

Minangkabau merupakan salah satu etnis yang ada di Sumatera Barat yang sangat menjunjung tinggi budaya dan adat istiadat. Yang memiliki nilai-nilai positif yang terkandung dalam setiap budayanya. Sesuai dengan filosofi Minangkabau "adat basandi syarak, syarak basandi kitabullah" (ABS-SBK) bahwa adat dan budaya yang islami ini merupakan cita-cita luhur nenek moyang yang harus dirawat, dijaga dan dilestarikan dengan mewariskannya dari generasi ke genarasi berikut dalam masyarakat.

$$
\text { Masyarakat Minangkabau }
$$
dikenal sebagai masyarakat yang 
religius, pekerja keras, menjunjung tinggi adat budaya, dan hidup selaras dengan alam. Masyarakat Minangkabau dulunya sangat menjunjung tinggi budaya gotong royong dan musyawarah dalam menyelesaikan suatu pekerjaan, baik bidang pertanian maupun kegiatan pembangunan di suatu nagari.

Namun, dalam kenyataan saat ini masyarakat Minangkabau cenderung menggunakan teknologi dan juga mengharapkan balasan atau upah, jika hanya sekedar gotong royong maka masyarakat akan terkesan acuh tak acuh. Nilai-nilai gotong royong atau tolong menolong sudah digantikan oleh sifat individual. Hal ini disebabkan kurangnya kesadaran diri dari setiap masyarakat untuk mau bergotong royong. Sehingga budaya gotong royong yang sangat kental dalam masyarakat Minangkabau perlahanlahan mulai dilupakan pada generasi muda.

Gejala fenomena lainnya, Masih banyaknya prilaku generasi muda di Minangkabau saat ini yang tidak sesuai dengan nilai-nilai budaya Minangkabau seperti, budaya berpakaian yang lebih ketat sehingga menampakkan lekuk tubuh dan terbuka yang meniru gaya hidup ke barat-baratan dimana tidak sesuai dengan budaya minang yang menganut nilai sopan santun dan ditunjang dengan mayoritas penduduknya beragama islam yang menjunjung tinggi cara berpakaian yang dapat menutup aurat.

Maka dari itu perlu adanya perhatian lebih oleh Pemerintah Daerah dengan situasi dan kondisi sekarang dimana zaman selalu mengalami perubahan ke arah modernisasi. Pemerintah Daerah membentuk organisasi perangkat daerah yaitu Dinas Kebudayaan yang bertugas dan bertanggung jawab terhadap segala hal yang terkait di bidang kebudayaan, karena berbagai perubahan yang terjadi harus disikapi dan diantisipasi agar dapat meminimalisir permasalahanpermasalahan yang terjadi dilingkungan masyarakat agar tidak semakin meluas untuk kedepannya.

\section{METODE PENELITIAN}

Penelitian ini merupakan penelitian kualitatif metode deskriptif. Pemilihan informan adalah dengan menggunakan purposive sampling, adapun yang menjadi informan dalam penelitian ini adalah Kasabug Program dan keuangan, Kabid Sejarah, adat dan nilai-nilai tradisi, Kabid kesenian dan diplomasi budaya, Kasi warisan budaya dan pamong budaya pertama. Jenis sumber penelitian ini adalah data primer dan data sekunder. Data terkumpul menggunakan observasi, wawancara dan studi dokumentasi. Analisis data dalam penelitian ini reduksi data, penyajian data dan penarikan kesimpulan.

\section{HASIL DAN PEMBAHASAN}

Program Pemberdayaan dan Penguatan Eksistensi Lembagalembaga Adat Seni dan Budaya

a. Penguatan Adat Nagari

Penguatan adat Nagari merupakan suatu aspek yang sangat penting untuk dikembangkan, karena sangat terkait dengan perilaku yang harus dilakukan oleh individu berdasarkan kepercayaan yang diyakininya. Penguatan adat nagari bertujuan untuk mengembalikan 
fungsi dan tanggung jawab dari masing-masing pemimpin kaum.

Kegiatan Penguatan adat Nagari dalam kegiatan pengangkatan penghulu yang dilakukan dalam Duduak Baropok yang merupakan salah satu cara masyarakat di Minangkabau mengambil keputusan berdasarkan mufakat yang terdapat nilai-nilai Musyawarah, nilai-nilai Gotong Royong/tolong menolong. Kegiatan ini pernah dilaksanakan di Kabupaten Tanah Datar, Pelaksananya Dinas Kebudayaan sebagai instansi Pembina dan dihadiri oleh Datuak, Niniak Mamak, alim ulama dan tokoh masyarakat. Kegiatan ini biasanya diadakan tiga kali dalam setahun dan dilakukan selama tiga hari disertai dengan pertunjukan kesenian untuk menghibur tamu dan makan bersama, seluruh lapisan masyarakat dalam nagari turut memeriahkan terutama pada acara puncak seperti mendengarkan pidato adat yang menyatakan tugas dan tanggung jawab penghulu baru.

Lembaga-lembaga yang terlibat dalam kegiatan ini ada Lembaga Kerapatan Adat Minangkabau (LKAM), Kerapatan Adat Nagari (KAN), Badan Musyawarah (Bamus). Dengan sasaran para pemuka adat dan masyarakat minangkabau yaitu tuo silek, tuo surau dan tuo dukun.

\section{b. Penerapan Nilai-nilai Adat Minangkabau Bagi Masyarakat dan Generasi Muda}

Dalam melestarikan nilai-nilai budaya, dinas kebudayaan Sumatera Barat melaksanakan beberapa bentuk kegiatan diantaranya, kegiatan randai, sipak rago, makan bajamba dan baju kurung basiba, ini merupakan tradisi Minangkabau dari sekian banyak tradisi seni pertunjukkan

Minangkabau. Pesertanya para komunitas sanggar dan masyarakat luas dari berbagai usia dan Dinas Kebudayaan Sumatera sebagai instansi pelaksana dan Pembina melalui Bimtek Pelaku Seni dan Kegiatan ini selalu dilaksanakan setiap tahunnya minimal 4-7 kali dalam satu tahun.

Didalam kegiatan ini sangat mengandung nilai-nilai kekeluargaan, moral dan nilai toleransi, dapat dilihat dalam kegiatan sipak rago yang pernah dilaksanakan di Kota Padang, yaitu Kuranji, Pauh dan nanggalo, didalam permainan sipak rago dimainkan oleh lima orang sampai sepuluh orang dengan cara membentuk lingkaran dilapangan terbuka.

Permainan sipak rago yang diutamakan adalah kekompakkan dan adanya sikap saling menghormati antara sesama pemain di dalam satu tim. Hal ini dapat dilihat dari cara meloncatkan bola rago ke teman yang berlawanan arah di depan kita dengan cara membungkukkan badan. Penghormatan kepada semua pemain juga terlihat dari cara pemberian bola atau umpan dari kaki ke kaki sesuai dengan kemampuan dan keahlian masing-masing pemain. Disinilah nilai-nilai kekeluargaan dan nilai toleransi itu terbentuk pada generasi muda selaku pelaku seni dan juga kegiatan makan bajamba yang pernah dilaksanakan di Kab Agam Nagari Koto Gadang, Makan bajamba adalah salah satu prosesi adat yang menggambarkan kehidupan komunal di Minangkabau.

Makan bajamba dilakoni oleh empat hingga enam orang yang makan bersama dalam satu piring 
besar yang disebut talam. Aturan duduk melingkar pun diatur dalam prosesi ini. Artinya, tidak boleh "centang parenang"(sesuka hati), melainkan diatur sedemikian rupa. Untuk kaum laki-laki duduk baselo (bersila) dan bagi padusi duduk basimpuah (bersimpuh).

Ada empat nilai-nilai budaya yang terkandung dalam prosesi makam bajamba. Pertama, nilai kekeluargaan yang dilihat dari prosesi makan bajamba, adanya rasa kebersamaan, karena makan bersama dapat menurunkan keberkahan pada makanan saat disantap bersama-sama. Kedua, nilai toleransi saat duduk dalam makan bajamba, semua orang dari strata sosial yang tinggi dan rendah tidak dibeda-bedakan. Ketiga, nilai moral (kontrol prilaku) untuk tidak bacapak (berbunyi) saat mengunyah dan mengajarkan betapa seseorang harus menimbang-nimbang untuk mengambil keuntungan pribadi dalam pergaulan di tengah-tengah masyarakat.

Dalam kegiatan baju kurung basiba dikenal sebagai pakaian adat perempuan Minangkabau. Hal ini dikarenakan baju ini menutup aurat dan longgar. Pakaian ini dikenakan lengkap dengan tingkuluak dan kain jao. Tidak semata-mata longgar melainkan memiliki makna yang sangat terkait dengan kebudayaan Minangkabau dan sangat menjunjung tinggi nilai moral. kegiatan komunitas baju kurung basiba Padang sering dilaksanakan setiap tahunnya di Kota Padang. Salah satunya dalam festival pemilihan Uda dan Uni Minangkabau yang dilaksanakan oleh dinas kebudayaan Sumatera Barat. lembaga yang terlibat dalam kegiatan ini adalah para komunitas Baju Basiba dan pengurus Bundo Kanduang.

c. Peningkatan wawasan adat bagi pengurus KAN, LKAM dan Bundo Kanduang

Kegiatan ini merupakan wadah untuk mendukung pencapaian sasaran pengelolaan kekayaan budaya Dinas Kebudayaan Provinsi Sumatera Barat, sesuai tugas fungsinya melaksanakan urusan wajib kebudayaan. Tujuan kegiatan untuk peningkatan wawasan adat bagi pengurus KAN, LKAM dan bundo kanduang dengan melakukan bimtek (bimbingan teknis) untuk meningkatkan kapasitas pengetahuan dan keterampilan bagi pemangku adat, yang pernah dilaksanakan di Tanah Datar. Sasarannya meningkatkan sumber daya manusia kebudayaan (pemangku adat, seniman, budayawan, masyarakat), agar dapat memahami tentang bagaimana melestarikan adat istiadat dan saling menjaga adat istiadat agar tidak punah karena kemajuan zaman.

Program Pembinaan dan Pengembangan Pendidikan Budaya

a. Pelestarian dan Aktualisasi nilai-nilai Matrilinial

Dinas kebudayaan Sumatera Barat menggelar kegiatan pelestarian kebudayaan Minangkabau melalui kegiatan lokakarya pelestarian dan aktualisasi nilai-nilai matrilineal. Kegiatan tersebut dilaksanakan di Padang. Kegiatan ini dilaksanakan sebagai salah satu upaya pelestarian nilai-nilai Matrilineal Minangkabau sebagai salah satu kearifan lokal yang menjadi identitas suku bangsa Minangkabau itu sendiri.

Perkembangan zaman dan tekanan budaya global melalui arus teknologi informasi yang tidak mengenal jarak ruang dan waktu 
dewasa ini tidak bisa dipungkiri telah menggerus nilai-nilai Matrilineal yang ada di Minangkabau. Nilai-nilai Matrilineal sangat identik dengan penarikan garis keturunan berdasarkan garis keturunan ibu dan mempunyai pola menetap Matrilokal, tempat tinggal secara berkelompok dalam satu keturunan berdasarkan garis keturunan ibu. Kegiatan ini diharapkan mampu meningkatkan pemahaman tentang sistem kekerabatan matrilineal (garis keturunan ibu) dan pewarisan sako dan pusako berdasarkan nilai-nilai Matrilineal yang ada.

\section{b. Sosialisasi pedoman pengamalan Adat Basandi Syarak Syarak Basandi Kitabullah Kepada kelompok masyarakat.}

Dalam mensosialisasikan visi dan memberikan arah serta tujuan yang akan diwujudkan, dan untuk memberikan fokus terhadap program yang akan dilaksanakan maka Pemerintah Provinsi Sumatera Barat menyatakan misi pembangunan jangka menengah Provinsi Sumatera Barat Tahun 2016-2021 dalam bentuk 5 (lima) misi. Tujuan pembangunan dinas kebudayaan Provinsi Sumatera Barat berada pada misi 1 yaitu Meningkatkan tata kehidupan yang harmonis, agamais, beradat dan berbudaya berdasarkan falsafah "Adat basandi syarak, syarak basandi kitabullah.

Adat basandi syara', syara' basandi kitabullah (adat harus didasarkan kepada agama, agama (Islam) berdasarkan Kitabullah (Al-Qur'an). Diperkuat lagi dengan pepatah-petitih penjelasan dan pendampingnya, seperti ungkapan: Syara' mangato adaik mamakai (agama islam memberikan fatwa adat yang melaksanakannya). Syara' bertelanjang adaik basisamping, (agama bersifat tegas dan lugas sedangkan adat mesti dilakukan sesuai dengan kondisi). Adat buruk (jahilliyah) dibuang dan baik (Islamiyah) dipakai, maksudnya adat baik sesuai dengan norma Islam harus dipertahankan dan disosilisasikan agar tidak habis sementara adat buruk yang bertentangan dengan nilai-nilai Islam harus dibuang.

Sosialisasi pedoman pengamalan adat basandi syarak syarak basandi kitabullah dilaksanakan di Padang pada hari rabu (17/10/2018) dengan sasaran seluruh lapisan masyarakat Minangkabau. Tujuan kegiatan Sosialisasi pedoman pengamalan adat basandi syarak syarak basandi kitabullah kepada kelompok masyarakat yang dilakukan oleh Dinas kebudayaan Sumatera Barat untuk memberikan arahan umum terhadap perilaku masyarakat Minangkabau yang mencerminkan kehidupan yang berakhlak berdasarkan ajaran islam, sesuai dengan adat nan bapaneh-syara' nan balinduang. Dengan harapan perilaku kehidupan masyarakat Minangkabau yang selaras dengan ajaran islam menjadi tradisi yang kuat. Sebagai salah satu upaya pelestarian nilai-nilai matrilineal Minangkabau sebagai salah satu kearifan lokal yang menjadi identitas suku bangsa Minangkabau itu sendiri.

c. Bimtek Penguatan Nilai-Nilai Budaya Bagi Ortu, Guru Dan Penggiat Himpunan Anak Usia Dini

Berdasarkan penelitian bahwa tujuan kegiatan bimtek penguatan nilai-nilai budaya bagi ortu, guru dan penggiat himpunan anak usia dini yang dilakukan oleh dinas kebudayaan Sumatera Barat berharap Penguatan nilai-nilai budaya 
diterapkan dimulai dari anak usia dini. Memberikan dan menanamkan kembali kepada masyarakat terhadap nilai-nilai budaya. Pada saat seminar di salah satu hotel di kota Padang tahun 2019 yang dihadiri orang tua, guru (pendidik), dan pemuka adat (bundo kanduang, niniak mamak). Dalam kegiatan tersebut terdapat penguatan nilai-nilai budaya bagi ortu, guru dan penggiat himpunan anak usia yaitu dalam berpakaian seragam sekolah PAUD, terbentuknya karakter orang tua dan guru PAUD bagi anak usia dini.

d. Sosialisasi Adat Minangkabau terhadap generasi muda yang mengacu kepada $A B S-S B K$

Sosialisasi adat Minangkabau terhadap generasi muda yang mengacu kepada $A B S-S B K$ bertujuan untuk memupuk rasa tanggung jawab dan kepedulian terhadap generasi muda. Kemudian untuk melestarikan budaya daerah dan untuk meningkatkan pengetahuan dan pemahaman generasi muda (Rang Mudo) tentang nilai adat dan budaya yang patut dijaga dan dilestarikan serta dilaksanakan, adat salingka Nagari yang harus di pedomani dan diterapkan dalam kehidupan seharihari.

Rang mudo sebagai orang Minang yang akan melanjutkan adat istiadat perlu sekali memahami dan mendalami adat istiadat minang salah satunya melalui berkarakter, santun dan peduli, para pemangku adat untuk lebih berperan meluruskan bentuk dari perilaku yang tidak sesuai dengan nilai-nilai adat tersebut. Dengan tujuan mencegah terjadinya perilaku negatif para rang mudo Minangkabau.
Program Dinas Kebudayaan Sumatera Barat dalam melestarikan nilai-nilai budaya Minangkabau

Program ini terkait dengan penguatan adat Nagari dinas kebudayaan Provinsi Sumatera Barat dalam pengangkatan penghulu terdapat nilai-nilai musyawarah dan mufakat, nilai-nilai gotong royong dan tolong menolong. Lebih lanjut dijelaskan oleh Muhlizi, (2019) bahwa dalam komunitas masyarakat adat yang belum terdafar pada pemberi Organisasi Bantuan Hukum (OBH) harus berafliasi dengan $\mathrm{OBH}$ Terakreditasi sehingga output kegiatannya jadi lebih jelas. Selain itu, jika paralegal komunitas tersebut berafliasi dengan $\mathrm{OBH}$ Terakreditasi maka paralegal tersebut dapat mengakses dana bantuan hukum yang diberikan melalui $\mathrm{OBH}$ tersebut. Selain itu, organisasi adat perlu memperoleh pelatihan dalam setiap program yang diadakan agar memadai dan memiliki standar kemampuan yang baik dalam kajian adat.

Dalam kegiatan penguatan adat Nagari terdapat nilai musyawarah, yang mana kegiatan yang dilaksanakan yaitu pengangkatan penghulu dalam duduak baropok yang pernah dilaksanakan di Kabupaten Tanah Datar, sedangkan nilai gotong royong terdapat dalam kegiatan alekalek Nagari yang mengakar disetiap nagari dalam membuat sebuah limbago adat atau organisasi yang dikerjakan secara bersama-sama demi kepentingan bersama oleh semua kaum masyarakat yang terlibat yang dapat meningkatkan silaturrahmi dan kerjasama dalam Nagari, yang tujuan untuk mengembalikan fungsi dan tanggung jawab dari masing-masing 
pemimpin kaum dengan mengamalkan falsafah hidup $A B S$ SBK. Kegiatan ini dilaksanakan di Agam dan Padang pada setiap tahun, dengan sasaran para pemuka adat dan masyarakat minangkabau yaitu tuo silek, Tuo Surau dan tuo dukun.

Kegiatan yang dilakukan oleh dinas kebudayaan berupa kegiatan dokumenter. Setiap peserta diminta membuat video Dokumenter mengenai tentang $A B S-S B K$, menceritakan kehidupan sehari-hari yang mencerminkan falsafah Minangkabau. Tujuan dari kegiatan tersebut agar generasi muda bisa memamparkan sebuah keterampilannya dibidang teknologi. Lebih lanjut Kosasih, (2013) mengemukakan Nagari di Minangkabau selain berfungsi sebagai pusat pemerintahan terendah dalam wilayah Republik Idonesia juga merupakan basis penanaman dan pelestarian nilai-nilai adat dan syarak. Kepemimpinan Nagari tidak hanya dilaksanakan oleh wali Nagari dan perangkat-peangkatnya sebagai pimpinan formal tapi juga oleh forum tigo tungku sajarangan (niniak mamak, alim ulama dan cadiak pandai) ditambah dengan unsur-unsur bundo kanduang sebagai pimpinan sosial. Masingmasing unsur harus saling bekerjasama dan bahu membahu sesuai fungsinya untuk mewujudkan cita-cita menuju kehidupan masyarakat Nagari yang makmur, sejahtera, aman, damai dan sentosa. Fungsi-fungsi tersebut akan dapat berjalan dengan baik dan lancar apabila masing-masing unsur memahami, menghayati dan mengamalkan nilai-nilai adat dan syari'at Islam seperti tertuang dalam ungkapan ABS-SBK.
Sejalan dengan temuan di atas, Yunarti, (2017) menjealskan bahwa permasalahan yang dihadapi perempuan dalam lingkup lembaga Bundo Kanduang di Nagari sebagai akibat dari kultur dan struktur di dalam masyarakat. Institusi bundo kanduang di Nagari sebagai basis pembangunan pemberdayaan perempuan secara empiris, hanya sub bagian dari lembaga yang menangani masalah sosial, pemuda, dan perempuan. Masih kentalnya bias gender di sebagian elit pemerintah, tokoh politik, tokoh masyarakat. Justru itu, perlu pengembangan institusi bundo kanduang di Nagari melalui pemberdayaan organisasi, personal dan pemberdayaan sosial, sehingga banyak tokoh-tokoh perempuan yang mampu bertindak sebagai agen bagi pemberdayaan perempuan di tingkat Nagari.

Dinas kebudayaan Sumatera Barat menggelar kegiatan pelestarian kebudayaan Minangkabau melalui kegiatan lokakarya pelestarian dan aktualisasi nilai-nilai matrilineal. Kegiatan tersebut dilaksanakan di hotel di Padang pada hari kamis hingga sabtu tanggal 9 sampai dengan 11 Agustus 2018 yang lalu. Dalam kegiatan tersebut yang dilaksanakan semala 3 hari didatangkan Narasumber dari seorang ulama yang berasal dari Aceh yang akan melihat aktualisasi nilai-nilai Matrilineal dari perspektif agama Islam. (Ariani, 2015) menjelaskan bahwa nilai-nilai yang terkandung dalam budaya matrilineal tersebut yang pada akhirnya memberikan masukan yang bagus untuk gerakan feminis di Indonesia agar mereka memperjuangkan hakhaknya sebagai kaum perempuan dengan berdasar pada budaya lokal, 
Volume 4 No. 22021

dan bukannya berdasar pada budaya Barat. Kosasih, (2013) mengemukakan kepemimpinan Nagari tidak hanya dilaksanakan oleh Wali Nagari dan perangkat-peangkatnya sebagai pimpinan formal tapi juga oleh forum tungku tigo sajarangan ditambah dengan unsur-unsur bundo kanduang sebagai pimpinan sosial. Masingmasing unsur harus saling bekerjasama dan bahu membahu sesuai fungsinya untuk mewujudkan cita-cita menuju kehidupan masyarakat Nagari yang makmur, sejahtera, aman, damai dan sentosa.

Sosialisasi adat Minangkabau terhadap generasi muda yang mengacu kepada $A B S-S B K$ yang dilakukan oleh dinas kebudayaan Sumatera Barat adalah kegiatan untuk memupuk rasa tanggung jawab dan kepedulian terhadap generasi muda. Bertujuan untuk melestarikan budaya daerah dan untuk meningkatkan pengetahuan dan pemahaman generasi muda tentang nilai adat danan budaya yang patut dijaga dan dilestarikan serta dilaksanakan, Adat Salingka Nagari yang harus di pedomani dan diterapkan dalam kehidupan sehari-hari. Lokasi kegiatan yang dilakukan oleh Dinas kebudayaan Sumatera Barat terdapat tiga lokasi yaitu Agam, solok, Padang.

Fimansyah, (2020) menjelaskan bahawa internalisasi pendidikan karakter berbasis kearifan lokal Minangkabau dapat terjadi melalui mata pelajaran Budaya Alam Minangkabau (BAM) atau mulok di Sumatera Barat, melalui cerita-cerita tradisional Minangkabau yang syarat akan nilai moral seperti Kaba namun sekarang sudah mulai ditinggalkan, serta melalui ungkapan-ungkapan bijak khas Minangkabau. Ditengah perkembangan zaman yang begitu pesat diharapkan internalisasi pendidikan karakter berbasis kearifan lokal ini dapat menanggulangi degradasi moral dikalangan generasi muda belakangan ini. Tidak hanya itu saja dengan mengimplementasikan nilai-nilai kearifan lokal dalam kehidupan sehari-hari berarti kita turut menjaga budaya lokal agar tetap eksis di tengah era globalisasi.

\section{KESIMPULAN}

Pogram Dinas Kebudayaan Sumatera Barat dalam melestarikan nilai-nilai budaya Minangkabau yaitu: (1) program pemberdayaan dan penguatan eksistensi lembagalembaga adat seni dan budaya meliputi: a) penguatan adat Nagari, b) penerapan nilai-nilai adat minangkabau bagi masyarakat dan generasi muda c) peningkatan wawasan adat bagi pengurus KAN dan Bundo Kanduang. (2) program pembinaan dan pengembangan pendidikan budaya meliputi: a) pelestarian dan aktualisasi nilai-nilai Matrilinial, b) Sosialisasi pedoman pengamalan Adat Basandi Syarak Syarak Basandi Kitabullah kepada kelompok masyarakat, c) bimtek penguatan nilai-nilai budaya bagi ortu, guru dan penggiat himpunan anak usia dini, dan d) sosialisasi adat minangkabau terhadap generasi muda yang mengacu kepada $A B S$ SBK

\section{DAFTAR PUSTAKA}

Abdurrahman. 2011. Nilai-nilai Budaya Dalam Minangkabau. UNP Press Padang.

Amir, M.S. 2007. Adat Minangkabau Pola dan Tujuan Hidup Orang 
Minang. Jakarta: PT. Mutiara Sumber Widya.

Koentjaraningrat. 2011. Pengantar Antropologi. Jakarta: PT Rineka Cipta. Koentjaraningrat. 2007. Manusia dan Kebudayaan di Indonesia. Jakarta: Djambatan.

Mulyana, Deddy. 2010. Metodologi Penelitian Kualitatif. Bandung: PT. Remaja Rosdakarya.

Murad, dkk. 2011. “Budaya Alam Minangkabau" (Bahan Ajar). Padang: Musyawarah Guru Mata Pelajaran BAM.

Meleong, Lexy J. 2012. Metode Penelitian Kulaitatif. Bandung: PT. RemajaEosdakarya.

Moleong, Lexy J. 2005. Metode Penelitian Kualitatif. Edisi Revisi, Cetakan Kedua Puluh Tujuh, Rosdi, Jakarta.

Hildigradis. 2019. Upaya Melestarikan Budaya Indonesia di Era Globalisasi. Jurnal Sosiologi Nusantara. Vol 5. No 1.

Octarina. 2015. Efektivitas Program Dinas Kebudayaan dan
Parawisata pada Pesta Budaya Tabuik di Kota Pariaman Sumatera Barat. Jurnal FISIP. Vol 1. No. 2.

Yunus, Rasyid. 2013. Tansformasi Nilai-nilai Budaya Lokal Sebagai Upaya Pengembangan Karakter Bangsa. Jurnal Penelitian Pendidikan. Vol 14. No. 1, April 2013.

Yunarti sri.2017. Pemberdayaan Lembaga Bundo Kanduang di Nagari Melalui Kebijakan Pembangunan yang Responsif Gender. Kafaah Journal, 7 (2), 2017, (221-234) (Print ISSN 23560894 Online ISSN 2356-0630) Available online at: http://kafaah.org/index.php/k a faah/index 